\title{
Ventilatory and gas exchange abnormalities on exercise in chronic heart failure
}

\author{
O.A. Al-Rawas*, R. Carter*, D. Richens**, R.D. Stevenson*, \\ S.K. Naik*, A. Tweddel*, D.J. Wheatley**
}

Ventilatory and gas exchange abnormalities on exercise in chronic heart failure. O.A. Al-Rawas, R. Carter, D. Richens, R.D. Stevenson, S.K. Naik, A. Tweddel, D.J. Wheatley. (C)ERS Journals Ltd 1995.

ABSTRACT: The mechanism of breathlessness on exertion in patients with chronic heart failure are still not fully understood. We therefore investigated the effects of ventilatory and gas exchange abnormalities on exercise capacity in chronic heart failure.

Exercise testing was performed in 30 patients with exertional breathlessness due to chronic heart failure and in $\mathbf{3 0}$ controls, using continuous transcutaneous blood gas monitoring.

Maximal symptom-limited oxygen consumption as $\left(V^{\prime} \mathrm{O}_{2}\right)$ as a percentage predicted was reduced in patients $(45 \pm 10 \%$; mean \pm SD) compared to controls $(87 \pm 7)$. The ventilatory response (minute ventilation/carbon dioxide production $\left(V^{\prime} \mathrm{E} / V^{\prime} \mathrm{CO}_{2}\right)$ ) was significantly increased in patients compared to controls $(39.9 \pm 7.7$ and $25.9 \pm 3.6$, respectively). The dead space to tidal volume ratio $(V \mathrm{D} / V \mathrm{~T})$ was raised in patients compared to controls at rest $(0.45 \pm 0.04$ vs $0.35 \pm 0.02$, respectively) and this persisted on exertion $(0.40 \pm 0.05$ in patients and $0.20 \pm 0.05$ in controls). At maximal symptomlimited exercise, $V^{\prime} \mathrm{E} / V^{\prime} \mathrm{CO}_{2}$ was inversely related to the \% predicted $V^{\prime} \mathrm{O}_{2}$ in patients, but not in controls ( $\mathrm{r}=-\mathbf{0 . 6 2}$ and $\mathrm{r}=-\mathbf{0 . 2 4}$, respectively). In patients, $V^{\prime} \mathrm{E} / V^{\prime} \mathrm{CO}_{2}$ was significantly correlated with $V \mathrm{D} / V_{\mathrm{T}}$ at maximum exercise $(\mathrm{r}=0.82)$.

Patients with chronic heart failure have a significant degree of "wasted ventilation" on exertion, which is associated with increased ventilatory response. The increased ventilatory response on exertion appears to contribute to exercise limitation in these patients.

Eur Respir J., 1995, 8, 2022-2028. *Dept of Respiratory Medicine and **Univer-
sity Dept of Cardiac Surgery, Royal Infirmary, Glasgow, Scotland.

Correspondence: O.A. Al-Rawas

Dept of Respiratory Medicine

Royal Infirmary

Glasgow G31 2ER

Scotland

Keywords: Exercise

heart failure

pulmonary gas exchange

ventilatory response

Received: August 311994

Accepted after revision June 251995
Breathlessness is a common, disabling symptom in patients with chronic heart failure [1]. There is accumulating evidence that the mechanisms of breathlessness in patients with chronic heart failure are complex and not related to the acute rise in pulmonary capillary wedge pressure during exercise [2-5]. Respiratory muscle weakness and abnormal ventilatory responses to exercise have been proposed as possible causes of breathlessness and exercise intolerance in this group [6-9].

Patients with chronic heart failure are characterized by excessive ventilatory response to exercise [8-11]. The role of this excessive ventilatory response in the sensation of dyspnoea and exercise intolerance is controversial [8, $9,12]$. In addition, the cause of this abnormality is not clear [13]. The early lactic acidosis, which is commonly observed in these patients plays an important role [2, 14, $15]$, but other factors independent of carbon dioxide production are also believed to contribute to the excessive ventilatory response in patients with chronic heart failure [13].

The aim of this study was to investigate the effects of ventilatory and gas exchange abnormalities on exercise capacity in patients complaining of breathlessness due to chronic heart failure, using continuous transcutaneous blood gas monitoring.

\section{Methods}

\section{Study Population}

Between June 1992 and June 1993, progressive cardiopulmonary exercise testing was performed in 30 patients (19 males, mean age $55 \mathrm{yrs}$, range $32-60 \mathrm{yrs}$, and 11 females, mean age 53 yrs, range 40-60 yrs) with chronic heart failure due to left ventricular dysfunction (mean left ventricular ejection fraction 16\%, range $7-32 \%)$. The mean height and weight were $169 \mathrm{~cm}$ and $69.8 \mathrm{~kg}$, respectively, for males, and $164 \mathrm{~cm}$ and $62.9 \mathrm{~kg}$, respectively, for females. All patients complained of breathlessness on exertion, and were referred from our heart transplant clinic as part of routine assessment for possible heart transplantation. Twelve patients were lifelong nonsmokers and the remaining 18 stopped 
smoking at least 2 yrs before the study (median 3 yrs, range 2-14 yrs) with a mean of 20 (range 4-64) packyears.

No patient had any evidence of primary lung disease and their resting pulmonary function as assessed by body plethysmography (PK Morgan, Rainham, UK) and single-breath transfer factor (Sensormedics UK Ltd) was within our laboratory normal range (mean $\pm 2 \mathrm{SD}$ ) (table 1). Twenty two patients had ischaemic heart disease and eight had idiopathic dilated cardiomyopathy. Antifailure medication consisted of diuretics (all patients), digoxin (14), angiotensin-converting enzyme inhibitors (24), and other vasodilators (13).

Findings were compared with those of age- and sexmatched controls recruited as volunteers from the general population, in whom there was no evidence of cardiorespiratory disease. Eight of the controls were lifelong nonsmokers, and the remainder were either ex-smokers (7), or current smokers (15), mean 22 (range 10-35) pack-years.

\section{Progressive exercise testing}

Symptom-limited exercise tests were performed using an electrically braked bicycle ergometer, with the patient breathing through a low dead space, low resistance valve box. The valve box incorporates a turbine ventilometer on the inspired limb for the measurement of inspired minute ventilation (Morgan, Rainham, UK). The expired limb is fed through a mixing chamber from which samples of expired air are analysed for the fractional concentrations of carbon dioxide and oxygen by an infrared spectrometer and paramagnetic analyser, respectively (PK Morgan, Rainham, UK). The gas analysers were calibrated with certified gas mixtures, and the pneumatograph system was verified using a $3 \mathrm{~L}$ calibration syringe before each exercise test.

Throughout each test, minute ventilation $\left(V^{\prime} \mathrm{E}\right)$, oxygen consumption $\left(V^{\prime} \mathrm{O}_{2}\right)$, and carbon dioxide production $\left(V^{\prime} \mathrm{CO}_{2}\right)$ were measured by on-line ventilation and expired gas analysis (PK Morgan Ltd, Rainham, UK) using standard equations [16]. The ventilatory anaerobic threshold on exertion was calculated by the curve fitting method, using a plot of $V^{\top} \mathrm{O}_{2}$ against $V^{\top} \mathrm{CO}_{2}$ [17].

Subjects were initially monitored for $2 \mathrm{~min}$ at rest whilst seated on the bicycle ergometer. They were then instructed to cycle with no additional load for 2 minutes.
The workload was then increased by increments of $25 \mathrm{~W}$ every 2 min until a symptom-limited maximum, and the primary symptom-limiting exercise was recorded.

Blood pressure was measured using a standard cuff sphygmomanometer at the end of each stage and a standard 12-lead electrocardiogram was displayed throughout the procedure. Our laboratory criteria for terminating the exercise before patients reach maximum symptomlimited point are ischaemic changes on electrocardiograph (ECG), ventricular arrhythmia, systemic hypotension (resting systolic blood pressure (BP) $<90 \mathrm{mmHg}$ or falling BP during exercise), or severe systematic hypertension (systolic BP > $220 \mathrm{mmHg}$ ). These changes did not occur in any of the study groups.

\section{Transactaneous blood gas monitoring}

Arterial blood gas values were monitored throughout exercise testing using a transcutaneous system (TCM3, Radiometer Ltd. Copenhagen, Denmark) heated to $45^{\circ} \mathrm{C}$ with the electrode attached to the flexor aspect of the forearm. Transcutaneous values of oxygen $\left(P \mathrm{tc}, \mathrm{O}_{2}\right)$ and carbon dioxide $\left(P \mathrm{tc}, \mathrm{CO}_{2}\right)$ tensions were continually monitored during the exercise test. The TCM3 monitoring system incorporates an automatic correction equation to correct the $P$ tc, $\mathrm{CO}_{2}$ back to the value that would be obtained at $37^{\circ} \mathrm{C}[18]$.

We have previously shown that the oxygen and carbon dioxide tension measured by the transcutaneous method correlate with the direct arterial oxygen and carbon dioxide tension $\left(\mathrm{Pa}, \mathrm{O}_{2}\right.$ and $\left.\mathrm{Pa}, \mathrm{CO}_{2}\right)$ measurement in haemodynamically stable patients at rest using an electrode temperature of $45^{\circ} \mathrm{C}$ [19]. This confirms the findings of previous studies $[20,21]$. Whilst there was no significant difference between the measurement of $\mathrm{Pa}, \mathrm{CO}_{2}$ and $P \mathrm{tc}, \mathrm{CO}_{2}$ in our study and a good correlation was evident between $P$ tc, $\mathrm{O}_{2}$ and $\mathrm{Pa}, \mathrm{O}_{2}$, the scatter of results showed that the $P$ tc, $\mathrm{O}_{2}$ could not predict the $P \mathrm{a}, \mathrm{O}_{2}$ with consistent accuracy when in vitro methods were used to calibrate transcutaneous monitor.

More controversy surrounds the use of $P \mathrm{tc}, \mathrm{CO}_{2}$ monitoring to reflect $P \mathrm{a}, \mathrm{CO}_{2}$ tensions during exercise testing. Using temperatures of $39-42^{\circ} \mathrm{C}$, there is a slow response time for the monitoring of changes which, in some cases, was up to $3 \mathrm{~min}$ [22]. Using a temperature of $45^{\circ} \mathrm{C}$, however, produces response times of the $P \mathrm{tc}, \mathrm{O}_{2}$ and $P \mathrm{tc}, \mathrm{CO}_{2}$

Table 1. - Resting pulmonary function in patients with chronic heart failure $(n=30)$

\begin{tabular}{|c|c|c|c|c|}
\hline & \multicolumn{2}{|c|}{ Males $(n=19)$} & \multicolumn{2}{|c|}{ Females $(n=11)$} \\
\hline & & $\%$ pred & & $\%$ pred \\
\hline VC L & $4.9(0.58)$ & $89(8)$ & $3.2(0.51)$ & $92(7)$ \\
\hline FEVI L & $4.1 \quad(0.49)$ & $88(6)$ & $2.5(0.42)$ & $92(6)$ \\
\hline FEV //FVC ratio & $80.9(5.7)$ & $106(10)$ & $76.0(4.8)$ & $95(9)$ \\
\hline RV L & $2.2(0.35)$ & $106(6)$ & $1.5(0.29)$ & $98(7)$ \\
\hline TLC L & $7.3(1.01)$ & 88 (4) & $4.5(0.99)$ & $95(5)$ \\
\hline $\mathrm{s} G$ aw $\mathrm{s} \cdot \mathrm{kPa}^{-1 *}$ & $1.6(0.31)$ & & $1.6(0.20)$ & \\
\hline KCO $\mathrm{mmol} \cdot \mathrm{min}^{-1} \cdot \mathrm{kPa} \cdot \mathrm{L}^{-1}$ & $1.5(0.15)$ & 78 (4) & $1.4(0.16)$ & $74(4)$ \\
\hline
\end{tabular}

Values are presented as mean, and SD in parenthesis. VC: vital capacity; FEV 1 : forced expiratory volume in one second; RV: residual volume (body plethysmograph); TLC: total lung capacity (body plethysmograph); sGaw: specific airways conductance; KCO: transfer coefficient for carbon monoxide; \% pred: percentage of predicted value. *: The lower limit of normal sGaw=1.1. 
electrode, to a change in breath pattern or inspired gas, of 30 or $55 \mathrm{~s}$, respectively [19]. These response times are of an order which has allowed the investigation of the use of the combined electrode for noninvasive monitoring of arterial blood gases during exercise testing. In addition the performance of an in vivo calibration using a sample of arterial or arterialized ear lobe capillary blood has been shown to improve the accuracy of the $P \mathrm{tc}, \mathrm{O}_{2}$ monitor by compensating for the difference between $P \mathrm{a}, \mathrm{O}_{2}$ in individual patients [23].

\section{Validation of transcutaneous monitoring}

We therefore validated the transcutaneous monitor in 24 patients referred for progressive cardiopulmonary exercise testing against direct arterial sampling from an indwelling arterial cannula [24]. The group comprised patients with a range of cardiopulmonary disorders of varying degrees of severity, and also included patients with chronic heart failure.

Following an in vivo calibration procedure with the transcutaneous electrode attached to the flexor surface of the forearm, a progressive exercise test was performed using an electrically braked bicycle ergometer. The $P \mathrm{tc}, \mathrm{O}_{2}$ and $P \mathrm{tc}, \mathrm{CO}_{2}$ were monitored for $2 \mathrm{~min}$ while the patient was seated at rest. An arterial blood sample was obtained at the mid-point of this period, and, taking into account the response time of the transcutaneous electrode, the transcutaneous monitor readings were recorded at the end of this period. The patient was then asked to exercise for as long as possible until symptomatic limitation. During the first 2 min of exercise, no additional load was applied and an arterial blood sample was obtained at the midpoint of this period. Transcutaneous values were recorded at the end of this period. Thereafter, the workload was increased by $10-25 \mathrm{~W}$, depending on the individual patient, every 2 min until symptomatic limitation. Blood samples were taken at the mid-point and transcutaneous values taken at the end of each workload period.

In the 24 patients, 140 simultaneous measurements of arterial blood gases and transcutaneous values were obtained following the in vivo calibration. The range of $P \mathrm{a}, \mathrm{O}_{2}$ measured was $6.1-14.2 \mathrm{kPa}$. The analysis of Bland and Altman on the two oxygen tension measurements showed a mean difference of $0.08 \mathrm{kPa}(0.62 \mathrm{mmHg}$; limits of agreement 4.42 and $-3.38 \mathrm{mmHg}$ ). The mean $P \mathrm{tc}, \mathrm{O}_{2}$ and $P \mathrm{a}, \mathrm{O}_{2}$ were $11.5 \pm 0.35$ and $11.5 \pm 0.33 \mathrm{kPa}$, respectively. Analysis of variance shows that there is no significant difference between these measurements $\mathrm{p}=0.94$ ). The in vivo calibration procedure produces an even scatter of results about the mean value with good limits of agreement, suggesting that there is no difference between the measurement of $P \mathrm{tc}, \mathrm{O}_{2}$ and $\mathrm{Pa}_{\mathrm{a}} \mathrm{O}_{2}$ on exercise testing.

The in vivo calibration procedure produced no adverse effects on the good relationship between $P \mathrm{tc}, \mathrm{CO}_{2}$ and $P \mathrm{a}, \mathrm{CO}_{2}$ already described. The $P \mathrm{a}, \mathrm{CO}_{2}$ ranged $3.6-7.6 \mathrm{kPa}$. The analysis of Bland and Altman showed a mean difference of $0.02 \mathrm{kPa}(0.22 \mathrm{mmHg}$; limits of agreement 2.2 and $-1.7 \mathrm{mmHg}$ ). The mean $P_{\mathrm{tc}}, \mathrm{CO}_{2}$ and $P \mathrm{a}, \mathrm{CO}_{2}$ were $5.6 \pm 0.2$ and $5.6 \pm 0.2 \mathrm{kPa}$, respectively, with no significant difference between the two measurements $(\mathrm{p}=0.89)$. In all the exercise tests, the trend of gas exchange as measured by the transcutaneous monitor was true to the trend as measured from direct arterial sampling. Using an exercise protocol of gradual workload increments of 2 min periods to prevent abrupt and large changes in blood gas tensions, and an electrode temperature of $45^{\circ} \mathrm{C}$ to produce response times of about $1 \mathrm{~min}$, allows changes in arterial blood gases to be closely followed by transcutaneous values.

In the present study, arterial blood gases were, therefore, monitored after an in vivo calibration period using the transcutaneous electrode. $P \mathrm{tc}, \mathrm{O}_{2}$ and $P \mathrm{tc}, \mathrm{CO}_{2}$ values were used to calculate alveolar-arterial oxygen gradient $\left(P_{\mathrm{A}-\mathrm{a}, \mathrm{O}_{2}}\right)$ and dead space tidal volume ratio $(V \mathrm{D} / V \mathrm{~T})$ using standard equations [16].

\section{Derived variables}

The following variables were calculated: maximal symptom-limited $V^{\prime} \mathrm{O}_{2}$. $\left(\mathrm{L} \cdot \mathrm{min}^{-1}\right) ; \mathrm{V}^{\prime} \mathrm{O}_{2}$ corrected for body weight $\left(\mathrm{mL} \cdot \mathrm{kg}^{-1} \cdot \mathrm{min}\right) ; V^{\prime} \mathrm{O}_{2}$ at anaerobic threshold $(\%$ predicted maximum $\left.V^{\prime} \mathrm{O}_{2}\right)$; ventilatory response equivalent for $\mathrm{CO}_{2}$ output $\left(V^{\prime} \mathrm{E} / V^{\prime} \mathrm{CO}_{2}\right) ; V_{\mathrm{D}} / V_{\mathrm{T}}$ ratio; alveolar arterial

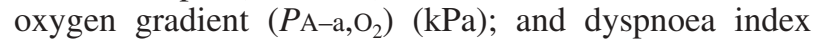
(maximum minute ventilation/maximum voluntary ventilation ( $\left.V^{\prime} \mathrm{E} / \mathrm{MVV}\right)$ ratio); with the predicted $\mathrm{MVV}^{\prime}$ $=37 \times \mathrm{FEV}_{1}$.

\section{Statistical Analysis}

All values are expressed as mean \pm SD. The maximal exercise values for patients and controls were compared to the normal values of Jones and CAMPBell [25]. The means of values obtained at maximum symptom-limited exercise were compared using Students' t-test. The mean values of maximal symptom-limited oxygen consumption as a percentage predicted were compared using Wilcoxon matched pairs test. The relationship between the slope of $V^{\prime} \mathrm{E} / V^{\prime} \mathrm{CO}_{2}$ and other variables $\left(V^{\prime} \mathrm{O}_{2}, V \mathrm{D} / V \mathrm{~T}\right)$ at maximal exercise in the patient group was analysed by linear regression. Values of $\mathrm{p}$ less than 0.05 were considered statistically significant.

\section{Results}

Resting and maximum exercise parameters in heart failure patients compared to age- and sex-matched controls are shown in table 2. There was no significant difference in resting $V^{\prime} \mathrm{O}_{2}$, heart rate (HR), or $P_{\mathrm{A}-\mathrm{a}, \mathrm{O}_{2}}$. Resting $V^{\prime} \mathrm{E}$ was higher in the cardiac failure group compared to controls but this difference did not reach statistical significance.

The responses to a symptom-limited progressive cardiopulmonary exercise test in heart failure patients compared to sex- and age-matched controls are shown in table 3 . The ventilatory response $\left(V^{\top} \mathrm{E} / V^{\prime} \mathrm{CO}_{2}\right)$ on exertion was significantly increased in patients with heart failure compared to controls (39.9 \pm 7.7 and $25.9 \pm 3.6$, respectively) $(\mathrm{p}<0.01)$. Maximal symptom-limited $V^{\mathrm{N}} \mathrm{O}_{2}$ as a percentage 
Table 2. - Resting and maximum symptom-limited exercise data in patients with chronic heart failure (CHF) compared to age- and sex-matched controls $(n=30)$

\begin{tabular}{|c|c|c|c|c|c|}
\hline \multirow[b]{3}{*}{$V^{\prime} \mathrm{O}_{2} \quad \mathrm{~L} \cdot \mathrm{min}^{-1}$} & \multicolumn{2}{|c|}{ Rest } & \multicolumn{3}{|c|}{ Maximum exercise } \\
\hline & $\mathrm{CHF}$ & Controls & $\mathrm{CHF}$ & \multicolumn{2}{|c|}{ Controls } \\
\hline & $0.27 \quad(0.03)$ & $0.25 \quad(0.02)$ & $0.93(0.20)$ & 1.99 & $(0.19)^{*}$ \\
\hline$V^{\prime} \mathrm{E} L \cdot \mathrm{min}^{-1}$ & $8.9 \quad(0.91)$ & $7.1 \quad(0.81)$ & $62.5 \quad(9.1)$ & 58.1 & $(6.7)$ \\
\hline HR beats $\cdot \min ^{-1}$ & $83.4 \quad(6.7)$ & $(6.4)$ & $141.9 \quad(8.4)$ & 152 & (7.9) \\
\hline$V_{\mathrm{T}} \mathrm{L}$ & $0.64(0.13)$ & $0.61 \quad(0.15)$ & $1.67(0.37)$ & 1.93 & $(0.43)^{*}$ \\
\hline$f \mathrm{R}$ breaths $\cdot \mathrm{min}^{-1}$ & $16.0 \quad(2.6)$ & $15.2 \quad(3.1)$ & $37.7 \quad(5.7)$ & 32.6 & (4.9) \\
\hline$V \mathrm{D} / V_{\mathrm{T}}$ ratio & $0.45(0.04)$ & $0.35(0.02)^{*}$ & $0.40 \quad(0.05)$ & 0.20 & $(0.05)^{*}$ \\
\hline$P_{\mathrm{A}-\mathrm{a}, \mathrm{O}_{2}} \mathrm{kPa}$ & $1.7 \quad(0.5)$ & $1.6 \quad(0.4)$ & $2.5 \quad(0.8)$ & 1.8 & $(0.6)$ \\
\hline
\end{tabular}

$V^{\prime} \mathbf{O}_{2}$ : oxygen uptake; $V^{\prime} \mathrm{E}$ : minute ventilation; HR: heart rate; $V \mathrm{~T}$ : tidal volume; fR: respiratory frequency; $V \mathrm{D} / V_{\mathrm{T}}$ : dead space/tidal volume ratio; $\mathrm{A}-\mathrm{a}, \mathrm{O}_{2}$ : alveolar-arterial oxygen gradient. *: $\mathrm{p}<0.001$.

of predicted was reduced in patients $(45 \pm 10)$ compared to controls $(87 \pm 7)(\mathrm{p}<0.001)$. Oxygen uptake at anaerobic threshold as a percentage of maximum predicted $V^{\prime} \mathrm{O}_{2}$ was also reduced $(30 \pm 5)$ compared to controls $(50 \pm 5)$ $(\mathrm{p}<0.005)$. Figure 1 shows the regression plot of the ventilatory response on exertion $\left(V^{\top} \mathrm{E} / V^{\top} \mathrm{CO}_{2}\right)$ against $\%$ predicted $V^{\prime} \mathrm{O}_{2}$ at maximum exercise in heart failure patients. There was a significant negative correlation between the ventilatory response on exertion and the maximal symptom-limited oxygen uptake as a percentage of predicted $(r=-0.62 ; p<0.001)$. In contrast, there was no correlation between these two variables in normal controls $(\mathrm{r}=-0.24 ; \mathrm{p}=0.06)$.

Dyspnoea was the primary symptom-limiting exercise in 20 patients and in 5 normal controls. In contrast, 5 patients with heart failure and 25 controls had leg fatigue as the primary symptom, and the remaining 5 patients reported dyspnoea and fatigue as equally limiting symptoms. The dyspnoea index ( $\left.V^{\mathrm{E}} \mathrm{E} / \mathrm{MVV}\right)$ at maximum symptom-limited exercise was similar in the two groups (heart failure $0.51 \pm 0.05$, controls $0.44 \pm 0.06$ ). Figure 2 shows the regression plot of dyspnoea index ( $\left.V^{\prime} \mathrm{E} / \mathrm{MVV}\right)$ against $\%$ predicted $V^{\prime} \mathrm{O}_{2}$ at maximum exercise. There was a significant negative correlation between the $V^{\prime} \mathrm{E} / \mathrm{MVV}$ at maximum exercise and the maximum $V^{\prime} \mathrm{O}_{2}$ achieved in heart failure patients $(\mathrm{r}=-0.65 ; \mathrm{p}<0.001)$.

Table 2 shows that the increased ventilatory response in patients with heart failure was associated with a raised

Table 3. - Maximum symptom-limited exercise response in chronic heart failure patients compared to ageand sex-matched controls $(n=30)$

\begin{tabular}{lclcll}
\hline Exercise variables & \multicolumn{1}{c}{ Controls } & \multicolumn{2}{l}{ Patients } & p-value \\
\hline$V^{\prime} \mathrm{O}_{2} \%$ pred & 87 & $(7)$ & 45 & $(10)$ & $<0.001$ \\
$V^{\prime} \mathrm{O}_{2} \mathrm{~mL} \cdot \mathrm{kg}^{-1} \cdot \min \%$ pred & 89 & $(6)$ & 43 & $(10)$ & $<0.001$ \\
$V^{\prime} \mathrm{O}_{2}, \mathrm{AT} \%$ & 50 & $(5)$ & 30 & $(5)$ & $<0.005$ \\
$V^{\prime} \mathrm{E} / V^{\prime} \mathrm{CO}_{2}$ & 25.9 & $(3.6)$ & 39.9 & $(9.7)$ & $<0.01$ \\
$V^{\prime} \mathrm{E} / \mathrm{MVV}$ & 0.44 & $(0.08)$ & $0.51(0.10)$ & $<0.05$
\end{tabular}

$V^{\prime} \mathrm{O}_{2}$, : maximal symptom-limited oxygen uptake; $V^{\prime} \mathrm{O}_{2}, \mathrm{~mL} \cdot \mathrm{kg}^{-1} \cdot \mathrm{min}$ maximal symptom-limited oxygen uptake corrected for body weight; $V^{\prime} \mathrm{O}_{2}$,AT: oxygen uptake at anaerobic threshold as a percentage of maximum predicted oxygen uptake; $V^{\prime} \mathrm{E} / \mathrm{V}^{\prime} \mathrm{CO}_{2}$ : ventilatory response equivalent for $\mathrm{CO}_{2}$ output; $\mathrm{V}^{\prime} \mathrm{E} / \mathrm{MVV}$ : dyspnoea index i.e. maximum minute ventilation/maximum predicted voluntary ventilation.

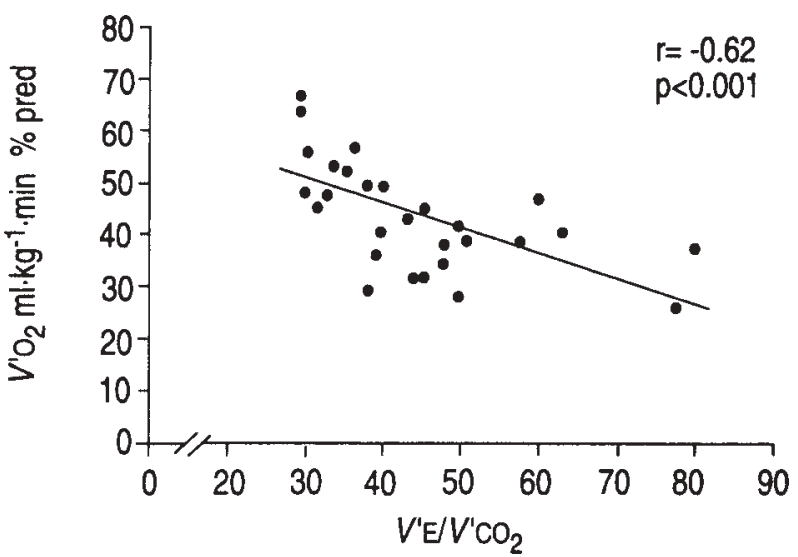

Fig. 1. - Regression plot of the ventilatory response equivalent for $\mathrm{CO}_{2}$ output $\left(V^{\prime} \mathrm{E} / V^{\prime} \mathrm{CO}_{2}\right)$ against the $\%$ predicted $(\%$ pred) maximal oxygen uptake corrected for body weight $\left(V^{\prime} \mathrm{O}_{2} \mathrm{~mL} \cdot \mathrm{kg}^{-1} \cdot \mathrm{min}\right)$ in 30 patients with chronic heart failure.

degree of "wasted ventilation". At rest, the degree of "wasted ventilation" as assessed by $V \mathrm{D} / V_{\mathrm{T}}$ ratio was significantly increased in heart failure patients compared to controls $(0.45 \pm 0.04$ and $0.35 \pm 0.02$, respectively) $(\mathrm{p}<0.001)$. At maximum symptom-limited exercise, $V_{\mathrm{D}} / V_{\mathrm{T}}$ decreased normally in controls, but persisted in patients, making the difference between the two groups greater than at rest $(0.40 \pm 0.05$ in heart failure and $0.20 \pm 0.05$ in

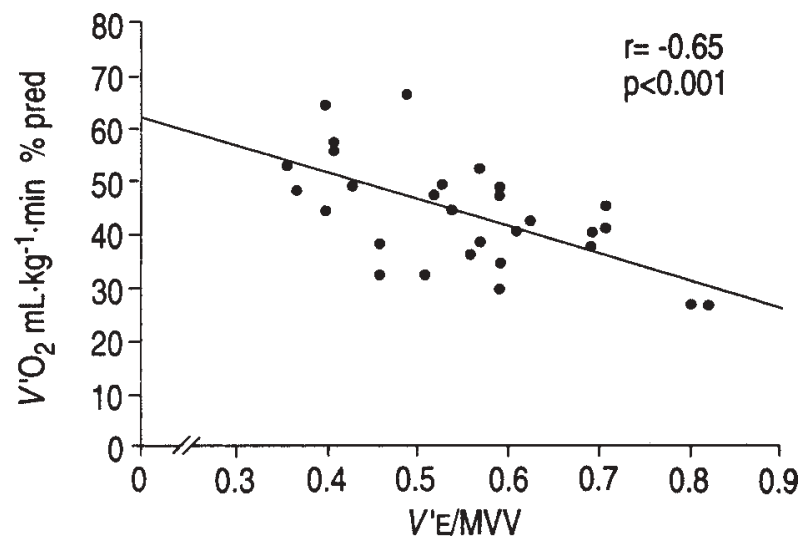

Fig. 2. - Regression plot of $V^{\prime} \mathrm{E} / \mathrm{MVV}$ (dyspnoea index i.e. maximum minute ventilation/maximum voluntary ventilation) agains \% (\% pred) predicted maximal corrected for body weight $\left(V^{\prime} \mathrm{O}_{2} \mathrm{~mL} \cdot \mathrm{kg}^{-1} \cdot \mathrm{min}\right)$ in 30 patients with chronic heart failure. 


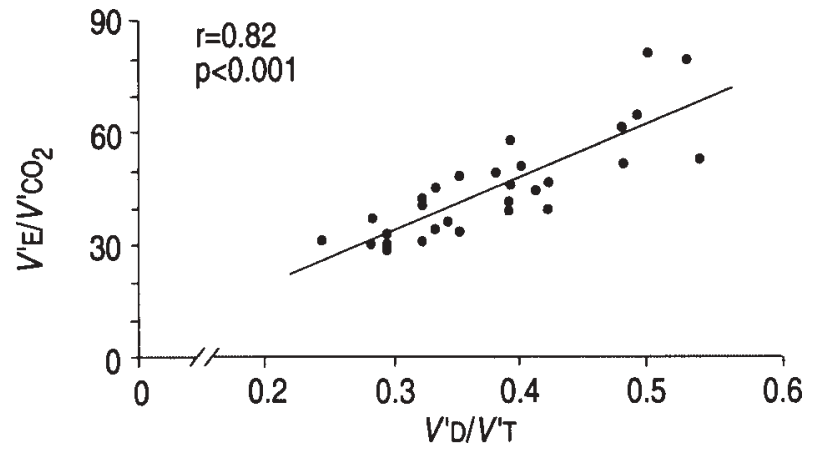

Fig. 3. - Regression plot of dead space/tidal volume ratio $\left(V_{\mathrm{D}} / V_{\mathrm{T}}\right)$ at maximum exercise against the ventilatory response equivalent for carbon dioxide output $\left(V^{\mathrm{E}} \mathrm{E} / V^{\prime} \mathrm{CO}_{2}\right)$ in 30 patients with chronic heart failure.

controls) $(\mathrm{p}<0.001)$. Although the $P \mathrm{~A}_{-} \mathrm{aO}_{2}$ gradient $(\mathrm{kPa})$ increased on exertion in heart failure patients compared to controls this did not reach statistical significance (at maximum exercise $2.5 \pm 0.8$ and $1.8 \pm 0.6$, respectively). Figure 3 shows the regression plot of $V \mathrm{D} / V \mathrm{~T}$ at maximum exercise against $V^{\top} \mathrm{E} / V^{\prime} \mathrm{CO}_{2}$ in heart failure patients. There was a significant positive correlation between the degree of "wasted ventilation" at maximum exercise and the ventilatory response on exertion $(r=0.82 ; \mathrm{p}<0.001)$.

The tidal volume at maximum symptom-limited exercise was significantly reduced in patients compared to controls $(1.67 \pm 0.37$ and $1.93 \pm 0.43 \mathrm{~L}$, respectively) $(\mathrm{p}=0.04)$. At maximum symptom-limited exercise, the respiratory frequency was increased in patients with heart failure compared to controls, but this did not reach statistical significance (37.7 \pm 5.7 and $32.6 \pm 4.9$, respectively).

\section{Discussion}

The role of excessive ventilatory response in exercise intolerance in chronic heart failure

Exercise intolerance is a major cause of morbidity in patients with chronic heart failure, even when they are on optimal medical treatment and free of symptoms at rest [26]. Fatigue, secondary to muscle underperfusion and deconditioning, is characteristic of chronic heart failure and is generally accepted as the primary cause of exercise limitation in this condition [2]. Breathlessness is a common disabling symptom in these patients [1]. It frequently coexists with fatigue, and in some patients it is the primary symptom [26].

Patients with chronic heart failure exhibit an excessive ventilatory response to exercise [8-11]. The role of this excessive ventilatory response in the sensation of exertional breathlessness and exercise intolerance is controversial. Some investigators have reported a significant association between the ventilatory response and maximal oxygen consumption [8, 9], with conflicting results in other studies $[2,12]$. The variation of results in these studies may, in part, reflect the heterogeneous populations of patients with chronic heart failure from various causes and of varying degrees of severity.

Our results in stable patients with advanced chronic heart failure confirm that excessive ventilatory response to exercise is characteristic of chronic heart failure. Furthermore, the ventilatory response at maximum symptomlimited exercise and the maximal symptom-limited oxygen uptake as a percentage of predicted were inversely related in heart failure patients. In contrast, there was no correlation between these two variables in controls. Patients with heart failure were more likely to stop exercising because of breathlessness than controls. In patients with heart failure, the dyspnoea index calculated as $V^{\mathrm{E}} \mathrm{E} / \mathrm{MVV}$ was inversely related to the maximal rate of oxygen consumption. These findings support the concept that the excessive ventilatory response may contribute to exercise intolerance in patients with chronic heart failure $[8,9]$.

\section{The mechanisms underlying the excessive ventilatory response}

The cause of increased ventilatory response to exercise in patients with chronic heart failure is uncertain. One major factor contributing to this excessive ventilatory response is the metabolic change in exercising muscles. Early lactic acidosis occurs in these patients resulting in increased carbon dioxide production, which stimulates ventilation to maintain normal blood $\mathrm{pH}[2,14,15]$. However, recent studies suggest that additional factors independent of carbon dioxide production may be involved in driving the excessive ventilation [13]. These include: abnormal control of breathing with rapid shallow breathing [14]; deconditioning [27]; and increased degree of "wasted ventilation" on exertion $[9,10,28]$.

Classically, it has been suggested that the acute rise in pulmonary venous pressure on exertion stimulates the juxtacapillary receptors, leading to rapid shallow breathing; thereby, increasing the ventilatory response and the work of breathing in these patients. However, there is now substantial evidence that exercise capacity is not related to the pulmonary capillary wedge pressure in these patients [13]. In addition, the finding that arterial carbon dioxide tension is normal at all levels of exercise suggests that the ventilatory control is normal in patients with chronic heart failure [10]. Exercise training in patients with chronic heart failure reduces the ventilatory response, and it is possible that this abnormality may be partly due to physical deconditioning [13, 27].

Another theory relates the elevated ventilatory requirement in patients with chronic heart failure to increased dead space ventilation and ventilation/perfusion abnormalities on exertion [9, 10, 28]. LEWIS et al. [28] compared the ventilatory cost of exercise in chronic heart failure and chronic anaemia. They demonstrated that exercise duration and maximum oxygen consumption were similarly reduced in the heart failure and anaemia groups compared to normal controls. The $V^{\prime} \mathrm{E} / V^{\prime} \mathrm{CO}_{2}$ slope, however, was normal in anaemic patients but steeper in patients with chronic heart failure, suggesting ventilation/perfusion mismatch rather than early lactic acidosis as the primary cause of excessive ventilatory response in 
chronic heart failure. METRA et al. [9] and Sullivan et al. [10] have demonstrated a significant correlation between the slope of $V^{\mathrm{E}} \mathrm{E} / V^{\prime} \mathrm{CO}_{2}$ and the $V \mathrm{D} / V_{\mathrm{T}}$ ratio. However, these studies have been criticized because of the equation used to derive $V \mathrm{D} / V_{\mathrm{T}}[13,29]$. They used the modified alveolar gas equation [30], which relates $V^{\top} \mathrm{E} / V^{\prime} \mathrm{CO}_{2}$ and $V_{\mathrm{D}} / V_{\mathrm{T}}$ in the following manner:

$$
V^{\prime} \mathrm{E}=V^{\prime} \mathrm{CO}_{2} \times 863 / P \mathrm{a}, \mathrm{CO}_{2} \times[1-(V \mathrm{D} / V \mathrm{~T})],
$$

and hence:

$$
V^{\prime} \mathrm{E} / V^{\prime} \mathrm{CO}_{2}=863 / P \mathrm{a}, \mathrm{CO}_{2} \times[1-(V \mathrm{D} / V \mathrm{~T})]
$$

where $P \mathrm{a}, \mathrm{CO}_{2}$ is arterial carbon dioxide tension and 863 is a constant to standardize gas measurements to body temperature, pressure and saturation. Because of their relationship in this equation, the two variables of interest $\left(V^{\prime} \mathrm{E} / V^{\prime} \mathrm{CO}_{2}\right.$ and $\left.V \mathrm{D} / V \mathrm{~T}\right)$ would necessarily correlate with each other without evoking any causal relationship.

Our study differs in that $V \mathrm{D} / V \mathrm{~T}$ was derived independently of the $V^{\top} \mathrm{E} / V^{\top} \mathrm{CO}_{2}$ relationship. We used the combined oxygen and carbon dioxide transcutaneous electrode, which has been validated previously $[19,24]$, to monitor arterial blood gas values throughout exercise testing noninvasively. This allowed the estimation of $V \mathrm{D} / V_{\mathrm{T}} \mathrm{using}$ the Bohr equation [16]:

$$
V \mathrm{D} / V \mathrm{~T}=\left(P \mathrm{a}, \mathrm{CO}_{2}-P_{\mathrm{E}, \mathrm{CO}_{2}}\right) / P \mathrm{a}, \mathrm{CO}_{2},
$$

where $P_{\mathrm{E}}, \mathrm{CO}_{2}$ is mixed expired carbon dioxide tension. The results of this study show that patients with chronic heart failure have an increased degree of "wasted ventilation" as assessed by $V_{\mathrm{D}} / V_{\mathrm{T}}$ ratio at rest, and this persisted on exertion. The level of wasted ventilation at maximum symptom-limited exercise was significantly correlated with the ventilatory response, confirming the findings of METRA et al. [9] and Sullivan et al. [10]. The elevated resting $V \mathrm{D} / V \mathrm{~T}$ as estimated using continuous transcutaneous monitoring of arterial blood gases is in agreement with the findings of RAJFER et al. [31], who used the same equation as in our study but with direct arterial blood sampling in 10 patients with chronic heart failure. In this investigation, the resting $V_{\mathrm{D}} / V_{\mathrm{T}}$ was elevated $(0.42 \pm 0.05)$ and declined at maximal exercise $(0.33 \pm 0.06)$. Unlike our findings, this decline was statistically significant, but $V \mathrm{D} / V \mathrm{~T}$ was still higher than would be expected in normal controls at maximal exercise (in our control group $V \mathrm{D} / V_{\mathrm{T}}$ decreased to $0.20 \pm 0.05$ ). The failure to decrease the level of wasted ventilation on exercise may be partially responsible for the excessive ventilatory response observed in patients with chronic heart failure.

The mechanism underlying the elevated $V \mathrm{D} / V_{\mathrm{T}}$ was not investigated in our study. Tachypnoea with shallow breathing and increased ventilation/perfusion mismatch have been suggested as possible causes [14, 28]. Increased pulmonary congestion on exercise would be expected to stiffen the lungs and stimulate the pulmonary juxtacapillary receptors, leading to tachypnoea with shallow breathing, and thereby raising the $V \mathrm{D} / V_{\mathrm{T}}[14]$. In our patients, the tidal volume was significantly lower in patients compared to controls at maximum symptomlimited exercise, but the respiratory frequency was not significantly different in the two groups. The levels of the respiratory frequency and tidal volume reached in patients with heart failure suggest that tachypnoea with shallow breathing pattern, which would produce a reduction in the alveolar ventilation compared to total ventilation, was not a major factor in the observed high $V \mathrm{D} / V_{\mathrm{T}}$ ratio on exertion in these patients. Increased ventilation/perfusion mismatch has been reported in patients with chronic heart failure during exercise [32, 33], and it has been suggested as a possible cause of the increased $V \mathrm{D} / V \mathrm{~T}$ [28]. It is not known whether the ventilation/perfusion abnormalities reflect a limited capacity to increase cardiac output compared to ventilation, or result from chronic pulmonary vascular and/or parenchymal damage secondary to chronic lung congestion.

\section{Study limitations}

The use of transcutaneous arterial blood gas monitoring in cardiopulmonary exercise testing is appealing, in that it is simple and noninvasive, and because it is continuous it provides more dynamic information than the standard static measurement of blood gas tensions. However, transcutaneous monitors also have important disadvantages that have limited their routine use in cardiopulmonary exercise testing, and arterial blood gas measurement by direct arterial cannulation remains the gold standard for the investigation of gas exchange mechanisms in the lungs [34]. It has been suggested that the slow response characteristics of the transcutaneous electrode for oxygen and carbon dioxide would render their use in exercise unreliable [34]. Another important limitation relevant to our patients is that transcutaneous measurements may not be reliable in patient with low cardiac output, especially those in shock [35].

Our patients had severe heart failure, but all were ambulatory stable out-patients and none of them developed hypotension on exercise. We have previously shown that the problem of slow response of the transcutaneous electrodes can be minimized by the use of the highest recommended temperature of $45^{\circ} \mathrm{C}$ combined with an exercise protocol of gradual workload increment of 2 min duration [19]. Using this protocol, we have validated the use of transcutaneous monitoring in cardiopulmonary exercise testing in patients with various cardiopulmonary disorders, including patients with heart failure [24].

The slow response of the $\mathrm{CO}_{2}$ electrode may underestimate the instantaneous $P$ a, $\mathrm{CO}_{2}$, but low skin perfusion has the opposite effect. If the net effect of these two factors was to underestimate carbon dioxide tension, this would lead to an apparent increase in the $V_{\mathrm{D}} / V_{\mathrm{T}}$ ratio derived using Bohr equation, and it might be suggested that this was the cause of the elevated $V_{\mathrm{D}} / V_{\mathrm{T}}$ observed in our patients. The normal decline in $V \mathrm{D} / V_{\mathrm{T}}$ in controls and the agreement between our results and others who used direct $P \mathrm{a}, \mathrm{CO}_{2}$ measurement, suggest that $V_{\mathrm{D}} / V_{\mathrm{T}}$ is truly elevated in patients with heart failure $[9,10,31]$. 
In conclusion, using completely noninvasive cardiopulmonary exercise testing, we found that patients with chronic heart failure have a significant degree of "wasted ventilation", which is associated with increased ventilatory response on exertion. The increased ventilatory response on exertion appears to contribute to exercise limitation in these patients. The elevated $V \mathrm{D} / V_{\mathrm{T}}$ on exertion in patients with heart failure is consistent with areas of the lungs being underperfused compared to their ventilation, but this remains to be determined.

\section{References}

1. Lipkin DP, Poole Wilson PA. Symptoms limiting exercise in chronic heart failure (editorial). Br Med J Clin Res 1986; 292: 030-1031.

2. Wilson JR, Ferraro N. Exercise intolerance in patients with chronic left heart failure: relation to oxygen transport and ventilatory abnormalities. Am J Cardiol 1983; 51: 13581363.

3. Franciosa JA, Leddy CL, Wilen M, Schwartz DE. Relation between hemodynamic and ventilatory responses in determining exercise capacity in severe congestive heart failure. Am J Cardiol 1984; 53: 127-134.

4. Lipkin DP, Canepa-Anson R, Stephens MR, PooleWilson PA. Factors determining symptoms in heart failure: comparison of fast and slow exercise tests. Br Heart J 1986; 55: 439-445.

5. Fink LI, Wilson JR, Ferraro N. Exercise ventilation and pulmonary artery wedge pressure in chronic stable congestive heart failure. Am J Cardiol 1986; 57: 249-253.

6. Mancini DM, Ferraro N, Nazzaro D, Chance B, Wilson JR. Respiratory muscle deoxygenation during exercise in patients with heart failure demonstrated with near infrared spectroscopy. J Am Coll Cardiol 1991; 18: 492-498.

7. McParland C, Krishnan B, Wang Y, Gallagher CG. Inspiratory muscle weakness and dyspnoea in chronic heart failure. Am Rev Respir Dis 1992; 146: 467-472.

8. Buller NP, Poole-Wilson PA. Mechanism of the increased ventilatory response to exercise in patients with chronic heart failure. Br Heart J 1990; 63: 281-283.

9. Metra M, Dei Cas L, Panina G, Visioli O. Exercise hyperventilation chronic congestive heart failure, and its relation to functional capacity and hemodynamics. Am J Cardiol 1992; 70: 622-628.

10. Sullivan MJ, Higginbotham MB, Cobb FR. Increased exercise ventilation in patients with chronic heart failure: intact ventilatory control despite haemodynamic and pulmonary abnormalities. Circulation 1988; 77: 552-559.

11. Myers J, Salleh A, Buchanan N, et al. Ventilatory mechanisms of exercise intolerance in chronic heart failure. Am Heart J 1992; 124: 710-719.

12. Wilson JR, Mancini DM, Farrel L. Excessive ventilatory levels do not limit the exercise capacity of patients with heart failure. Circulation 1992; 86(4): 1-339

13. Clark AL, Coats A. The mechanisms underlying the increased ventilatory response to exercise in chronic stable heart failure. Eur Heart J 1992; 13: 1698-1708.

14. Weber KT, Kinasewitz GT, Janicki JS, Fishman AP. Oxygen utilisation and ventilation during exercise in patients with chronic cardiac failure. Circulation 1982; 65: 1213-1223.
15. Reddy HK, Weber KT, Janicki JS, McElroy PA. Hemodynamic, ventilatory and metabolic effects of light isometric exercise in patients with chronic heart failure. J Am Coll Cardiol 1988; 12: 353-358.

16. Cotes JE. Lung Function. 4th edn. Oxford, Blackwell Scientific Publications, 1978; p.212.

17. Beaver WL, Wasserman K, Whipps BJA. New method for detecting anaerobic threshold by gas exchange. J Appl Physiol 1986; 60: 2020-2027.

18. Siggard-Anderson O. In: The Acid-Base Status of Blood. Copenhagen, Munksgaard; 1976; p.89.

19. Carter R. The measurement of transcutaneous oxygen and carbon dioxide tensions during exercise testing. Breath 1989; 38: 2-6.

20. Mahutte CK, Michiels TM, Hassell KT, Trueblood DM. Evaluation of a single transcutaneous $P_{\mathrm{O}_{2}}-\mathrm{PCO}_{2}$ sensor in adult patients. Crit Care Med 1984; 12: 1063-1066.

21. Hutchison DC, Rocca G, Honeybourne D. Estimation of arterial oxygen tension in adult subjects using a transcutaneous electrode. Thorax 1981; 36: 473-477.

22. Nickerson BG, Paterson C, McCrea R, Monaco F. In vivo response times for a heated skin surface $\mathrm{CO}_{2}$ electrode during rest and exercise. Ped Pulmonol 1986; 2: 135-140.

23. Gray BJ, Heaton RW, Henderson A, Hutchison DC. Continuous transcutaneous monitoring. In: Huch A, Huch R, Rooth G, eds. Advances in Experimental Medicine and Biology. New York, Plenum Press, 1987; pp. 75-78.

24. Sridhar MK, Carter R, Moran F, Banham SW. Use of combined oxygen and carbon dioxide transcutaneous electrode in the estimation of gas exchange during exercise. Thorax 1993; 48: 643-647.

25. Jones NL, Campbell EJM. Clinical Exercise Testing. 2nd edn. Toronto, Saunders; 1982;

26. Wilson JR, Mancini DM. Factors contributing to the exercise limitation of heart failure. J Am Coll Cardiol 1993; 22: 93A98A.

27. Davey P, Meyer T, Coats A, et al. Ventilation in chronic heart failure: effects of physical training. Br Heart J 1992; 68: 473-477.

28. Lewis NP, MacDougall IC, Willis N, Henderson AH. The ventilatory cost of exercise compared in chronic heart failure and chronic renal anaemia. QJ Med 1992; 83: 523-531.

29. Clark AL, Coats AJ. Exercise hyperventilation chronic congestive heart failure and its relation to functional capacity and hemodynamics (letter; comment). Am J Cardiol 1993; 71: 1007-1008.

30. Whipp BJ. Ventilatory control during exercise in humans. Ann Rev Physiol 1983; 45: 393-413.

31. Rajfer SA, Nemanich JW, Shurman AJ. Metabolic responses to exercise in patients with heart failure. Circulation 1987; 76(Suppl.): 46-53.

32. Wada O, Asanoi H, Miyagi K, et al. Importance of abnormal lung perfusion in excessive exercise ventilation in chronic heart failure. Am Heart J 1993; 125: 790-798.

33. Mohsenifar Z, Amin DK, Shah PK. Regional distribution of lung perfusion and ventilation in patients with chronic congestive heart failure and its relationship to cardiopulmonary hemodynamics. Am Heart J 1989; 117: 887-891.

34. Clark JS, Votteri B, Ariagno RL, et al. State of the art: noninvasive assessment of blood gases. Am Rev Respir Dis 1992; 45: 220-232.

35. Tremper KK, Shoemaker WC. Transcutaneous oxygen monitoring of critically ill adults, with and without low flow shock. Crit Care Med 1981; 9: 706-709. 